OPEN ACCESS

Edited by:

Shinkichi Takamori, National Hospital Organization Kyushu

Cancer Center, Japan

Reviewed by:

Andrea Bonetti,

Azienda UIss 9 Scaligera, Italy

Seiji Niho,

Dokkyo Medical University, Japan Yuyan Wang,

Beijing Cancer Hospital, China

Chunxia Su,

Shanghai Pulmonary Hospital, China

*Correspondence:

Chao H. Huang chuang2@kumc.edu

Specialty section: This article was submitted to

Thoracic Oncology, a section of the journal

Frontiers in Oncology

Received: 13 February 2021 Accepted: 06 May 2021

Published: 11 June 2021

Citation:

Atieh T and Huang $\mathrm{CH}$ (2021) Treatment of Advanced-Stage

Large Cell Neuroendocrine

Cancer (LCNEC) of the Lung:

A Tale of Two Diseases.

Front. Oncol. 11:667468.

doi: 10.3389/fonc.2021.667468

\section{Treatment of Advanced-Stage Large Cell Neuroendocrine Cancer (LCNEC) of the Lung: A Tale of Two Diseases}

\author{
Tahani Atieh $^{1}$ and Chao H. Huang ${ }^{1,2 *}$ \\ 1 Division of Medical Oncology, Department of Medicine, University of Kansas Medical Center, Kansas City, \\ KS, United States, 2 Subpecialty Medicine, Kansas City VA Medical Center, Kansas City, MO, United States
}

LCNEC of the lung comprises a small proportion of pulmonary malignancies. Traditionally, they have been classified based on histologic and immunohistochemistry characteristics with features of small cell and non-small cell lung cancer. The treatment outcome of advanced-stage LCNEC of the lung is poor with response rates ranging from 34 to $46 \%$ with platinum doublets, median progression-free survival (mPFS) ranging between 4.4 and $5.8 \mathrm{~m}$, and median overall survival (mOS) ranging from 8 to $12.6 \mathrm{~m}$. The optimal treatment strategy for LCNEC is debated given limited data and different outcomes based on chemotherapy type reported in the available literature. Recently, genomic profiling with Next Generation Sequencing (NGS) has been able to sub-classify LCNEC as SCLC-like or NSCLC-like. Treatment based on this sub-classification has improved outcomes by using SCLC and NSCLC regimens based on their genomic profile in retrospective analysis. Future studies in LCNEC of the lung should incorporate this new molecular subclassification as stratification and possibly include SCLC-like LCNEC into SCLC studies and NSCLC-like into NSCLC studies.

Keywords: LCNEC, large cell neuroendocrine carcinoma, molecular profile, treatment, lung cancer, classification

\section{INTRODUCTION}

LCNEC of the lung comprises about 2 to $3.5 \%$ of all lung cancers. It is more frequent in males, with a median age of 65 years, and smokers (1). Travis et al. first described the LCNEC type of lung cancer in 1991 characterized by large cells with abundant cytoplasm, necrotic areas, high mitotic rate, and neuroendocrine features (2).

In 2004, The World Health Organization (WHO) classified LCNEC as a variant of large cell carcinomas. The 2015 update now has LCNEC in a group of neuroendocrine neoplasms with SLCL, typical carcinoids (TC), and atypical carcinoids (3). Karlson et al. showed through gene expression profiling that the WHO 2015 guidelines translated into a better transcriptional subgrouping of large cell carcinomas compared to the 2004 guidelines, but their analysis included a limited number of LCNEC and stressed the need for further molecular studies to tailor treatment (4). 


\section{PATHOLOGY}

The pathology of LCNEC is characterized by large cell size, abundant necrosis, low nuclear/cytoplasm ratio, neuroendocrine differentiation pattern associated with organoid nests, trabecular, rosette, and palisade formation. It also has a granular chromatin pattern, clear or atypical nucleoli. It has neuroendocrine markers such as chromogranin, neuron-specific enolase, synaptophysin, and somatostatin $(3,5)$. Pulmonary LCNEC shares pathologic features with atypical carcinoid in terms of growth pattern with LCNEC having more necrosis (6). The mitotic rate is usually high between 11 or more per 10 high power fields. A high mitotic rate helps differentiate between atypical carcinoid and small cell lung cancer (7). There could be features of non-small cell squamous or adenocarcinoma differentiation which is classified as mixed LCNEC. Because of these mixed features, it is not uncommon for mixed LCNEC to be diagnosed as poorly differentiated NSCLC or misclassified as atypical carcinoid or small cell lung cancer.

\section{TREATMENT OF ADVANCE STAGE LCNEC}

The treatment results of advanced-stage LCNEN have been controversial with retrospective studies showing conflicting results with SCLC regimens compared with NSCLC regimens. Please see Table 1. Sun et al. showed that the response rate was $73 \%$ using an SCLC regimen of cisplatin with etoposide compared with a response of $50 \%$ with NSCLC regimens (8). This was not the case in the retrospective review by Fujiwara et al. in which cisplatin with irinotecan had a lower response of $55 \%$ compared with a response rate of $71 \%$ with paclitaxel-based chemotherapy (9). A retrospective analysis by Naidoo et al. of 49 patients with stage IV LCNEC showed an ORR of $37 \%$ with firstline platinum/etoposide while no patients receiving nonplatinum-based regimens had a response (10). The use of second-line therapy with Amrubicin by Yoshida et al. showed a low response rate of $27.7 \%$ and mPFS of 3.1 and mOS of $5.1 \mathrm{~m}$ (11). Immune checkpoint inhibitor (CKI) has been used to treat LCNEC, showing a response rate of $33 \%$, mPFS of $4.2 \mathrm{~m}$, and mOS of 11.8 months (12). These retrospective studies are limited by a small sample size and limited mutational analysis.

Prospective phase II trials showed response rates in the range of 34 to $46 \%$, with platinum doublets and mPFS between 4.4 and $5.8 \mathrm{~m}$, and $\mathrm{mOS}$ ranging from 8 to $12.6 \mathrm{~m}(13,14)$. The addition of Everolimus to paclitaxel and carboplatin in a German study did increase response or improvement in mPFS and mOS (15).

\section{MOLECULAR CLASSIFICATION AND OUTCOME}

The availability of sequencing technology has allowed further insights into the genomic make-up of LCNEC. This genomic characterization has implications in predicting chemotherapy outcome as two distinct molecular profiles have arisen: a molecular profile that behaves and responds like SCLC, and another profile that behaves and responds like NSCLC. The indication that LCNEC has genomic similarities with SCLC has been documented in early studies of immunochemistry and genomic expression comparing LCNEC and SCLC. These studies showed commonality with multiple genes and signal transduction pathways. The most common are TP53 and RB1 mutations, with TP53 mutation occurring in 75 to $95 \%$ of SCLC and 71 to $95 \%$ of LCNEC. The RB1 mutation occurs in 41 to $91 \%$ of SCLC and slightly lower at 26 to 38\% of LCNEC (16).

RAS pathway alteration is also common in both disease states. An analysis of 15 LCNEC cases showed that it had an immunochemical expression of p53, point mutation of p53, cRAF-1, and K-ras-2 indicating genetic similarity with SCLC (17). The PI3K/AKT/mTOR pathway alterations are commonly present in SCLC and LCNEC. A study from Japan performed genomic profile of SCLC and LCNEC and found similar genomic changes in the PI3K/AKT/mTOR pathway: PI3KCA (3\%), PTEN (4\%), AKT2 (4\%) RICTOR (5\%), mTOR (1\%) and alterations in EGFR (1\%), ERBB2 (4\%) and FGFR1 (5\%) in LCNEC compared with 4, 6, 2, 6, 1,1 and $3 \%$ in SCLC respectively. Certain mutations seem to be more frequent in LCNEC, including LAMA1 (10\%), PCLO (6\%) and MEGF8 (5\%) compared to SCLC. Copy numbers of ERBB2 and SETBP1 occurred in 4\% of LCNEC (17). Other mutations were more frequent in SCLC, including the MYC amplification which occurs in $18-30 \%$ of SCLC compared to $23 \%$ of LCNEC. LCNEC can also have a genomic profile similar to NSCLC with alterations in SKT-11, KRAS, and KEAP1 (16). These studies showed that LCNEC is in reality two types of lung cancer; SCLCsubtype and NSCLC-subtype based on genomic profile.

A recent paper proposed a new molecular classification of LCNEC: type I with STK11/KEAP1 alterations, but with an NE phenotype, high expression of ASCL1 and DLL3, and downregulation of NOTCH pathway, as in the SCLC classical subtype; type II characterized by RB1 alterations, but a predominant non-NE phenotype (with low expression of chromogranin A and synaptophysin), high levels of REST and $\mathrm{NOTCH}$, and immune cell response activation more responsive to NSCLC type therapy (18). A study in 94 cases of stage IV LCNEC showed DLL3 expression in $74 \%$ of cases. It was also positive in $76 \%$ of $\mathrm{pRB}$ negative, and $67 \%$ of $\mathrm{pRB}$ positive patients; $79 \%$ of RB1 mutated, and $70 \%$ of RB1 wildtype patients; $100 \%$ of STK11 mutated, $91 \%$ in KEAP1 mutated, and in $100 \%$ of cases with TP53 wildtype tumors. DLL3 expression was also associated with expression of ASCL1 and at least two out of three neuroendocrine markers (19).

Rekhtman et al. performed NGS in pulmonary LCNEC and found altered TP53 (78\%), RB1 (38\%), STK11 (33\%), KEAP1 (31\%), and KRAS (22\%) and segregated LCNEC into two main different molecular subtypes: SCLC-like with TP53/RB1 inactivation and MYCL amplification; NSCLC-like with retained TP53/RB1 functions, NOTCH mutations and also with STK11/KRAS/TTF1 mutations, similar to that of adenocarcinoma, or KEAP1 mutations or SOX2/FGFR1 amplification, as with squamous cell carcinoma. They also proposed a third carcinoid subtype that had inactivation of MEN1 mutations and low mutation burden like carcinoid (20). 
TABLE 1 | Summary of treatments in LCNEC.

\begin{tabular}{|c|c|c|c|c|c|}
\hline Study & Line of therapy & Regimen & ORR & mPFS & mos \\
\hline $\begin{array}{l}\text { GFPC } 0302 \text { study } \\
\text { Prospective phase II }\end{array}$ & Frontline & Cisplatin + Etoposide & $34 \%$ & $5 \mathrm{~m}$ & $8 \mathrm{~m}$ \\
\hline $\begin{array}{l}\text { Niho et al. Japan. } \\
\text { Prospective phase II }\end{array}$ & Frontline & Cisplatin + Irinotecan & $46.7 \%$ & $5.8 \mathrm{~m}$ & $12.6 \mathrm{~m}$ \\
\hline $\begin{array}{l}\text { Christopoulos et al. German } \\
\text { Prospective phase II }\end{array}$ & Frontline & Everolimus with paclitaxel and carboplatin & $45 \%$ & $4.4 \mathrm{~m}$ & $9.9 \mathrm{~m}$ \\
\hline $\begin{array}{l}\text { Fujiwara et al. } \\
\text { Retrospective review }\end{array}$ & Frontline & $\begin{array}{l}\text { Cisplatin + Irinotecan } \\
\text { Paclitaxel-based }\end{array}$ & $\begin{array}{c}55.6 \% \\
71 \%\end{array}$ & $4.1 \mathrm{~m}$ & $10.3 \mathrm{~m}$ \\
\hline $\begin{array}{l}\text { Sun et al. } \\
\text { Retrospective review }\end{array}$ & Frontline & $\begin{array}{l}\text { Platinum + Etoposide/ } \\
\text { Platinum + Taxane/gemcitabine/ } \\
\text { pemetrexed/vinorelbine/EGFR TKI }\end{array}$ & $\begin{array}{l}73 \% \\
50 \%\end{array}$ & $\begin{array}{l}6.1 \mathrm{~m} \\
4.9 \mathrm{~m}\end{array}$ & $\begin{array}{l}16.5 \mathrm{~m} \\
9.2 \mathrm{~m}\end{array}$ \\
\hline $\begin{array}{l}\text { Yoshida et al. } \\
\text { Retrospective review }\end{array}$ & Second line & Amrubicin & $27.7 \%$ & $3.1 \mathrm{~m}$ & $5.1 \mathrm{~m}$ \\
\hline $\begin{array}{l}\text { Sherman et al. } \\
\text { Retrospective review }\end{array}$ & $\begin{array}{l}10 \% \text { 1st line } \\
80 \% \text { 2nd line } \\
10 \% \text { beyond } 2 \text { nd line }\end{array}$ & Checkpoint inhibitor & $33 \%$ & $4.2 \mathrm{~m}$ & $11.8 \mathrm{~m}$ \\
\hline
\end{tabular}

Similarly, George et al. used whole-exome/genome sequencing showed that LCNEC is composed of two mutually exclusive subgroups: "type I LCNECs" with bi-allelic TP53 and STK11/ KEAP1 alterations (37\%), and "type II LCNECs" enriched for biallelic inactivation of TP53 and RB1 (42\%). Type I LCNECs with high neuroendocrine expression and, similar to SCLC, a profile of ASCL1 high/DLL3 high/NOTCH low, and type II LCNECs with reduced expression of neuroendocrine genes and a pattern of ASCL1 low/DLL3 low/NOTCH high (21). Derks et al. performed next-generation sequencing (NGS) and determined the TP53, RB1, STK-11, KEAP-1, and IHC for RB1 and P16 in patients with LCNEC and correlated mutations with treatment and clinical outcomes. This study found the frequency of RB1 mutation and protein loss to be 47 and $72 \%$ respectively. Cases with LCNEC with $\mathrm{RB}$ wild type treated with gemcitabine with taxane had significantly longer overall survival compared with those treated with small cell platinum and etoposide (PE) regimen. This study indicated that LCNEC with wild type RB1 treated with gemcitabine and taxane had a better outcome than using PE (22). Another study profiled tumor DNA and circulating tumor DNA (ctDNA). Commonly altered genes in these LCNEC tumors included TP53 (75\%), RB1 (32.1\%), SMARCA4 (21.4\%), NOTCH1 (17.9\%), KEAP1 (17.9\%) with few cases of KRAS, EGFR, and CDKN2A mutations and STK11 mutation or loss (see Figure 1). The study then classified LCNEC as SCLC-like if RB1 or TP53 were mutated or had copy number loss and as NSCLC-like LCNEC if patients did not have RB1 and TP53 co-alterations (23).

In a case series of 95 LCNEC samples, 16\% expressed PD-L1 and $5 \%$ had a tumor proportion score (TPS) of $\geq 50 \%$. Its expression was equal in RB1 mutated and RB1 wild-type tumors. None of the STK11 mutated tumors expressed PD-L1. PD-L1 expression was correlated with superior overall survival (OS), hazard ratio 0.55 [(95\% Confidence Interval 0.31-0.96), $\mathrm{p}=0.038]$ (24). These studies showed that LCNEC should have a molecular profile done to distinguish if it is NSCLC-like or SCLC-like so that we can tailor the chemotherapy regimen. The studies using NGS to determine the genomic profile of LCNEC separated them into SCLC-like or NSCLC-like were able to show a different outcome when the cases are selected and treated based on their SCLC-like or NSCLC-like classification.

While NGS is timely and costly, IHC staining for RB1 and TP53 protein is readily available with much lower cost and may be a substitute to NGS to potentially differentiate these two subtypes (25). In a retrospective analysis, Myoshi et al. found that most of the RB1-mutated samples (93\%) were negative for RB staining, and there was mutual exclusivity of protein expression between RB and p16 (26).

In a study by Karlson et al. also tumor protein p53 gene (TP53) and RB1 mutations were found in 91 and $82 \%$ of LCNEC tumors, respectively, with RB1 mutations always concurrently with TP53 mutations, and 91\% of cases showed absent RB1 protein expression. Further, RB1 mutations seem to happen in a mutually exclusive way with mutations in STK11, KEAP1, and the KRAS/NRAS/HRAS pathway genes (27).

Based on this information, it seems rational to start separating LCNEC based on genomic profile and classify them as SCLCsubtype, NSCLC-subtype, Carcinoid-subtype, and choose the regimen based on their genomic profile. See Figure 2.

\section{CONCLUSION}

The nature of pulmonary LCNEC has been an ongoing enigma for the last several decades. LCNEC are diagnosed histologically with features of either small cell or non-small cell lung cancer. Early immunohistochemistry studies of pulmonary LCNEC also 


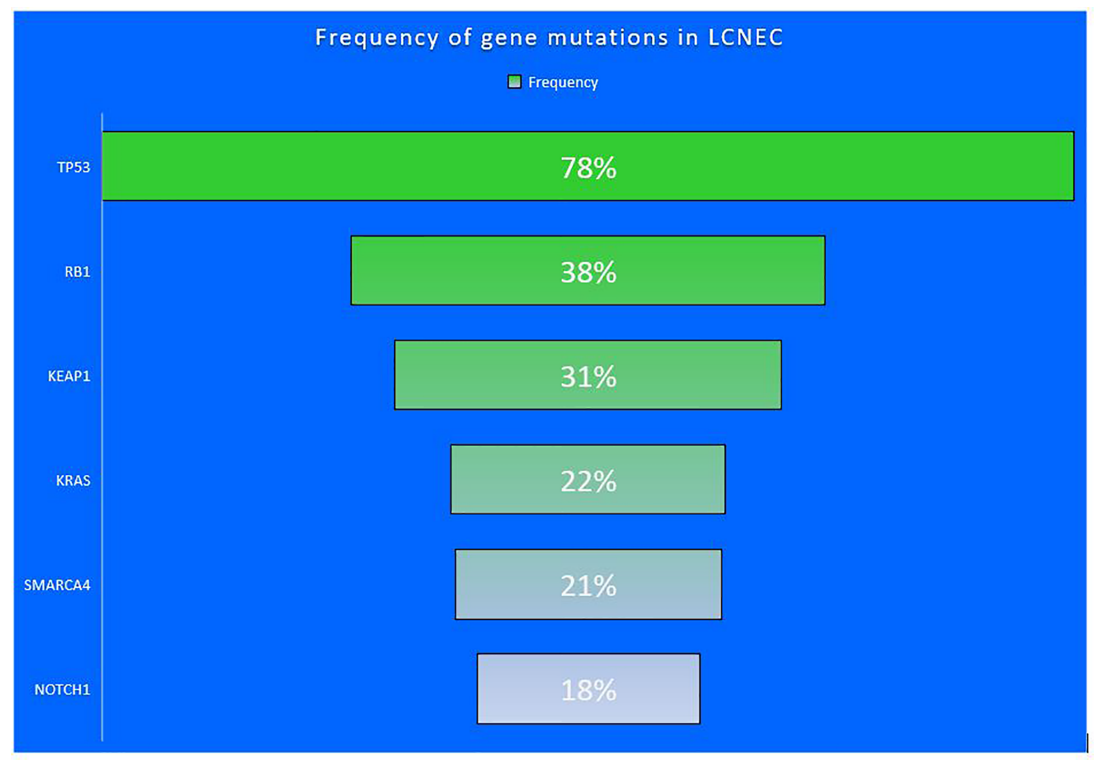

FIGURE 1 | Frequency of gene mutations seen in LCNEC.

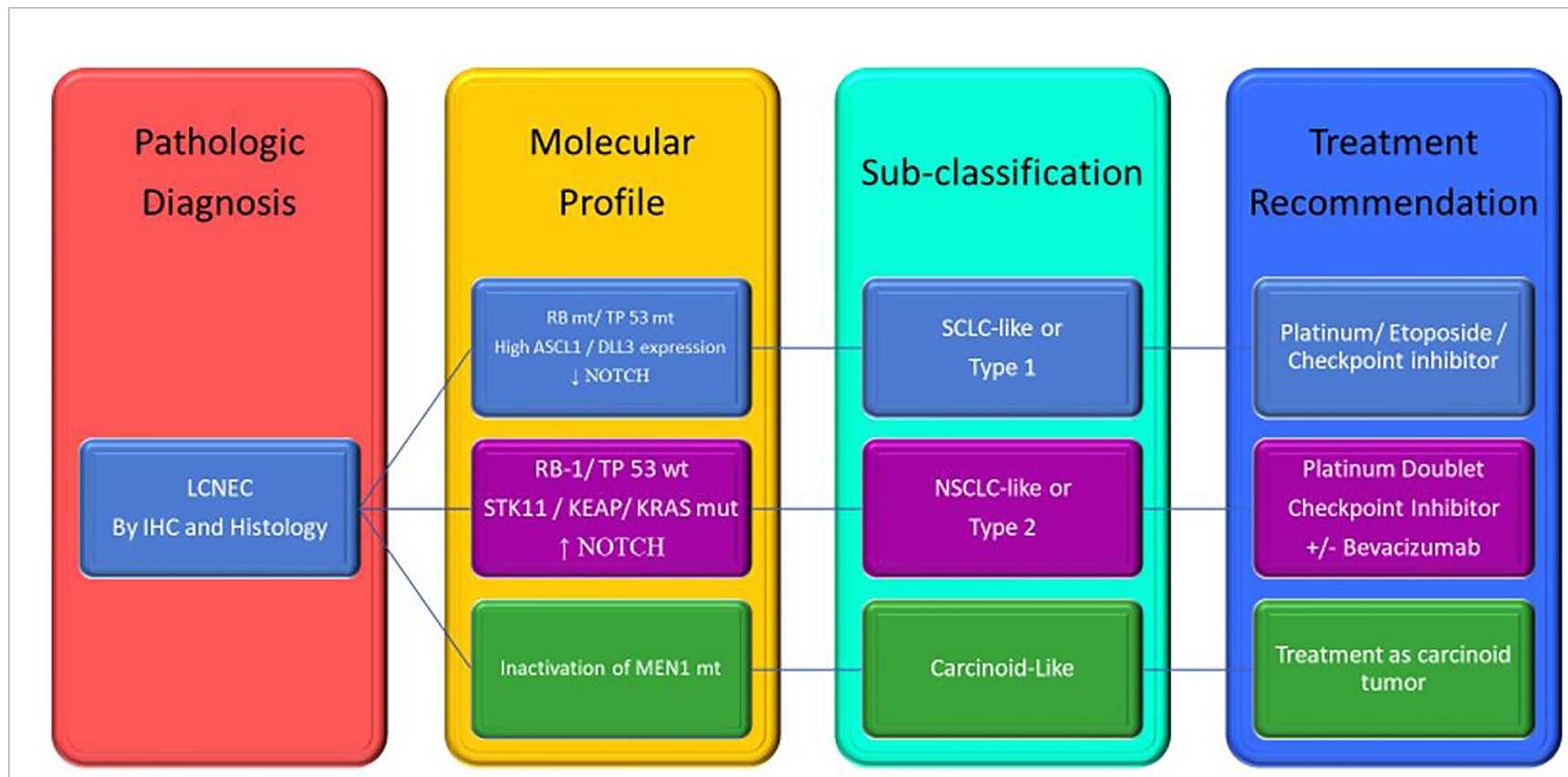

FIGURE 2 | Proposed of LCNEC sub-classification based on genomic changes and treatment recommendation. LCNEC, large cell neuroendocrine cancer; IHC, immunochemistry; mt, mutant; wt, wild type; SCLC, small cell lung cancer; NSCLC, non-small cell lung cancer. Adapted from Rekhtman et al. (20).

showed this dichotomy, demonstrating alterations of RB1 and TP53 common in SCLC with other samples lacking alterations of RB1 or TP53. Further molecular studies confirmed what was seen in the histologic and immunohistochemistry studies. They further confirmed the presence of dual molecular profiles of pulmonary LCNEC with an SCLC-subtype with mutations in RB1, TP53,
MYCL amplification, and alterations in the PI3K/AKT/mTOR pathway; NSCLC-subtype with mutations in SKT-11, KEAP, and KRAS. A small subset of LCNEC has alterations of MEN-1 with histologic features of carcinoid. The emerging data is starting to define that pulmonary LCNEC is akin to Janus, the ancient god with two faces indicating the beginning and the end of the 
conflict, with two main subtypes: SCLC-subtype and NSCLCsubtype. This subclassification has treatment implications. The outcome of pulmonary LCNEC is worse than the typical NSCLC, likely because some of them have a natural history similar to SCLC. The overall treatment outcome of advanced LCNEC is generally poor with 5-year survival ranging from 15 to $25 \%$. The treatment of advanced metastatic LCNEC generally consisted of an SCLC regimen of platinum and etoposide. Other trials have used regimens tailored toward NSCLC.

Recently, several papers proposed to use molecular profile testing to first sub-classify LCNEC into an SCLC-subtype or NSCLC-subtypes. The outcome of SCLC-subtype and NSCLCsubtype LCNEC seems to have a better outcome if they are treated based on the respective subtype of LCNEC as demonstrated by trials using this approach. This certainly makes clinical sense as the current treatment approach is to customize the treatment using an SCLC or NSCLC regimen. The use of molecular profile to make the treatment decision would make this a rational choice as opposed to an intuitive choice. The availability of next-generation sequencing technology should make the adoption of molecular subclassification of LCNEC seemly in the current practice setting. We may not necessarily have to wait for confirmation of prospective trials using the approach of managing LCNEC based on molecular classification. Instead, we should focus our resources and research efforts on the identification of effective therapy for LCNEC. Future trials in lung cancer should include SCLC-subtype and NSCLC-subtype of LCNEC in respective disease state studies to answer important questions regarding the use of immunotherapy and specific targeted therapy so that we can move this field forward. This will expedite the approval of new treatment options and truly make an impact on the management of pulmonary LCNEC.

\section{AUTHOR CONTRIBUTIONS}

TA and CHH: wrote, edited, reviewed, and finalized tables and figures. TA helped edit and review the current manuscript. All authors contributed to the article and approved the submitted version.

\section{REFERENCES}

1. Fasano M, Della Corte CM, Papaccio F, Ciardiello F, Morgillo F. Pulmonary Large-Cell Neuroendocrine Carcinoma: From Epidemiology to Therapy. J Thorac Oncol (2015) 10(8):1133-41. doi: 10.1097/JTO.0000000000000589

2. Travis WD, Linnoila RI, Tsokos MG, Hitchcock CL, Cutler GB Jr, Nieman L, et al. Neuroendocrine Tumors of the Lung With Proposed Criteria for LargeCell Neuroendocrine Carcinoma. An Ultrastructural, Immunohistochemical, and Flow Cytometric Study of 35 Cases. Am J Surg Pathol (1991) 15(6):52953. doi: 10.1097/00000478-199106000-00003

3. Travis WD World Health Organization. International Agency for Research on Cancer., International Association for the Study of Lung Cancer., International Academy of Pathology. In: Pathology and Genetics of Tumours of the Lung, Pleura, Thymus and Heart, vol. 344. Lyon Oxford: IARC Press Oxford University Press (distributor) (2004).

4. Karlsson A, Brunnstrom H, Micke P, Veerla S, Mattsson J, La Fleur L, et al. Gene Expression Profiling of Large Cell Lung Cancer Links Transcriptional Phenotypes to the New Histological WHO 2015 Classification. J Thorac Oncol (2017) 12(8):1257-67. doi: 10.1016/j.jtho.2017.05.008

5. Iyoda A, Hiroshima K, Nakatani Y, Fujisawa T. Pulmonary Large Cell Neuroendocrine Carcinoma: its Place in the Spectrum of Pulmonary Carcinoma. Ann Thorac Surg (2007) 84(2):702-7. doi: 10.1016/j.athoracsur.2007.03.093

6. Liang R, Chen TX, Wang ZQ, Jin KW, Zhang LY, Yan QN, et al. A Retrospective Analysis of the Clinicopathological Characteristics of Large Cell Carcinoma of the Lung. Exp Ther Med (2015) 9(1):197-202. doi: 10.3892/ etm.2014.2075

7. Chen LC, Travis WD, Krug LM. Pulmonary Neuroendocrine Tumors: What (Little) Do We Know? J Natl Compr Canc Netw (2006) 4(6):623-30. doi: 10.6004/jnccn.2006.0051

8. Sun JM, Ahn MJ, Ahn JS, Um SW, Kim H, Kim HK, et al. Chemotherapy for Pulmonary Large Cell Neuroendocrine Carcinoma: Similar to That for Small Cell Lung Cancer or Non-Small Cell Lung Cancer? Lung Cancer (2012) 77 (2):365-70. doi: 10.1016/j.lungcan.2012.04.009

9. Fujiwara Y, Sekine I, Tsuta K, Ohe Y, Kunitoh H, Yamamoto N, et al. Effect of Platinum Combined With Irinotecan or Paclitaxel Against Large Cell Neuroendocrine Carcinoma of the Lung. Jpn J Clin Oncol (2007) 37 (7):482-6. doi: 10.1093/jjco/hym053

10. Naidoo J, Santos-Zabala ML, Iyriboz T, Woo KM, Sima CS, Fiore JJ, et al. Large Cell Neuroendocrine Carcinoma of the Lung: Clinico-Pathologic Features, Treatment, and Outcomes. Clin Lung Cancer (2016) 17(5):e121e9. doi: 10.1016/j.cllc.2016.01.003

11. Yoshida H, Sekine I, Tsuta K, Horinouchi H, Nokihara H, Yamamoto N, et al. Amrubicin Monotherapy for Patients With Previously Treated Advanced Large-Cell Neuroendocrine Carcinoma of the Lung. Jpn J Clin Oncol (2011) 41 (7):897-901. doi: 10.1093/jjco/hyr065

12. Sherman S, Rotem O, Shochat T, Zer A, Moore A, Dudnik E. Efficacy of Immune Check-Point Inhibitors (ICPI) in Large Cell Neuroendocrine Tumors of Lung (LCNEC). Lung Cancer (2020) 143:40-6. doi: 10.1016/ j.lungcan.2020.03.008

13. Le Treut J, Sault MC, Lena H, Souquet PJ, Vergnenegre A, Le Caer H, et al. Multicentre Phase II Study of Cisplatin-Etoposide Chemotherapy for Advanced Large-Cell Neuroendocrine Lung Carcinoma: The GFPC 0302 Study. Ann Oncol (2013) 24(6):1548-52. doi: 10.1093/annonc/mdt009

14. Niho S, Kenmotsu H, Sekine I, Ishii G, Ishikawa Y, Noguchi M, et al. Combination Chemotherapy With Irinotecan and Cisplatin for Large-Cell Neuroendocrine Carcinoma of the Lung: A Multicenter Phase II Study. J Thorac Oncol (2013) 8(7):980-4. doi: 10.1097/JTO.0b013e31828f6989

15. Christopoulos P, Engel-Riedel W, Grohe C, Kropf-Sanchen C, von Pawel J, Gutz S, et al. Everolimus With Paclitaxel and Carboplatin as First-Line Treatment for Metastatic Large-Cell Neuroendocrine Lung Carcinoma: A Multicenter Phase II Trial. Ann Oncol (2017) 28(8):1898-902. doi: 10.1093/annonc/mdx268

16. Hiroshima K, Mino-Kenudson M. Update on Large Cell Neuroendocrine Carcinoma. Transl Lung Cancer Res (2017) 6(5):530-9. doi: 10.21037/ tlcr.2017.06.12

17. Przygodzki RM, Finkelstein SD, Langer JC, Swalsky PA, Fishback N, Bakker A, et al. Analysis of P53, K-ras-2, and C-raf-1 in Pulmonary Neuroendocrine Tumors. Correlation With Histological Subtype and Clinical Outcome. Am J Pathol (1996) 148(5):1531-41.

18. Lantuejoul S, Fernandez-Cuesta L, Damiola F, Girard N, McLeer A. New Molecular Classification of Large Cell Neuroendocrine Carcinoma and Small Cell Lung Carcinoma With Potential Therapeutic Impacts. Transl Lung Cancer Res (2020) 9(5):2233-44. doi: 10.21037/tlcr-20-269

19. Hermans BCM, Derks JL, Thunnissen E, van Suylen RJ, den Bakker MA, Groen HJM, et al. DLL3 Expression in Large Cell Neuroendocrine Carcinoma (LCNEC) and Association With Molecular Subtypes and Neuroendocrine Profile. Lung Cancer (2019) 138:102-8. doi: 10.1016/j.lungcan.2019.10.010

20. Rekhtman N, Pietanza MC, Hellmann MD, Naidoo J, Arora A, Won H, et al. Next-Generation Sequencing of Pulmonary Large Cell Neuroendocrine Carcinoma Reveals Small Cell Carcinoma-like and Non-Small Cell Carcinoma-like Subsets. Clin Cancer Res (2016) 22(14):3618-29. doi: 10.1158/1078-0432.CCR-15-2946 
21. George J, Lim JS, Jang SJ, Cun Y, Ozretic L, Kong G, et al. Comprehensive Genomic Profiles of Small Cell Lung Cancer. Nature (2015) 524(7563):47-53. doi: 10.1038/nature14664

22. Derks JL, Leblay N, Thunnissen E, van Suylen RJ, den Bakker M, Groen HJM, et al. Molecular Subtypes of Pulmonary Large-Cell Neuroendocrine Carcinoma Predict Chemotherapy Treatment Outcome. Clin Cancer Res (2018) 24(1):33-42. doi: 10.1158/1078-0432.CCR-17-1921

23. Zhuo M, Guan Y, Yang X, Hong L, Wang Y, Li Z, et al. The Prognostic and Therapeutic Role of Genomic Subtyping by Sequencing Tumor or Cell-Free DNA in Pulmonary Large-Cell Neuroendocrine Carcinoma. Clin Cancer Res (2020) 26(4):892-901. doi: 10.1158/1078-0432.CCR-19-0556

24. Hermans BCM, Derks JL, Thunnissen E, van Suylen RJ, den Bakker MA, Groen HJM, et al. Prevalence and Prognostic Value of PD-L1 Expression in Molecular Subtypes of Metastatic Large Cell Neuroendocrine Carcinoma (LCNEC). Lung Cancer (2019) 130:179-86. doi: 10.1016/ j.lungcan.2019.02.022

25. Baine MK, Rekhtman N. Multiple Faces of Pulmonary Large Cell Neuroendocrine Carcinoma: Update With a Focus on Practical Approach to Diagnosis. Transl Lung Cancer Res (2020) 9(3):860-78. doi: 10.21037/ tlcr.2020.02.13

26. Miyoshi T, Umemura S, Matsumura Y, Mimaki S, Tada S, Makinoshima H, et al. Genomic Profiling of Large-Cell Neuroendocrine Carcinoma of the
Lung. Clin Cancer Res (2017) 23(3):757-65. doi: 10.1158/1078-0432.CCR16-0355

27. Derks JL, Leblay N, Lantuejoul S, Dingemans AC, Speel EM, FernandezCuesta L. New Insights Into the Molecular Characteristics of Pulmonary Carcinoids and Large Cell Neuroendocrine Carcinomas, and the Impact on Their Clinical Management. J Thorac Oncol (2018) 13(6):752-66. doi: 10.1016/j.jtho.2018.02.002

Conflict of Interest: The institution where $\mathrm{CH}$ worked received research funding from the following companies to conduct clinical trials: Genentech/Roche, Bayer, Bristol-Mayers, Incyte, Sanofi, Astra Zeneca, Nektar, RGX, and Pfizer.

The remaining author declares that the research was conducted in the absence of any commercial or financial relationships that could be construed as a potential conflict of interest.

Copyright (C) 2021 Atieh and Huang. This is an open-access article distributed under the terms of the Creative Commons Attribution License (CC BY). The use, distribution or reproduction in other forums is permitted, provided the original author(s) and the copyright owner(s) are credited and that the original publication in this journal is cited, in accordance with accepted academic practice. No use, distribution or reproduction is permitted which does not comply with these terms. 